\title{
Evolution of green in-situ generated polyamide nanofibers controlled by viscoelasticity
}

\author{
R. Hosseinnezhad, I. Vozniak ${ }^{*}$, J. Morawiec, A. Galeski \\ Centre of Molecular and Macromolecular Studies, Polish Academy of Sciences, Sienkiewicza 112, 90-363 Łodz, Poland
}

Received 12 June 2020; accepted in revised form 15 August 2020

\begin{abstract}
The study scrutinizes the coincidental formation and stabilization of bio-based polyamide (PA) nanofibers within biodegradable polylactide (PLA) in a single stage. The results reveal that the formation of nanofibril-matrix morphology is dominated by viscosity and elasticity ratios of the dispersed component to the matrix. It is shown that there are upper and lower bounds for the ratios providing efficient in situ fibrils formation. For PLA/PA, critical values of viscosity and elasticity ratios are in the range of 0.3-2.8 and 2.0-15.0, respectively. As these parameters decrease, thinner and longer PA nanofibers form, and ultimately a network of nanofibrils develops. Below the lower boundary, formed very thin, less than $250 \mathrm{~nm}$, nanofibrils become unstable, and their flow is accompanied by breaking-up into sub-nanodroplets. Above the upper boundary, the viscosity of the polymer matrix is insufficient to arrange droplets to fibers transitions, and the presence of a compatibilizer can only lead to a partial formation of a fibrillar structure. The shear-induced crystallization is proposed for the stabilization of PA nanofibers immediately under applying a high shear rate without subsequent cooling. A higher effect (more significant increase in the crystallization temperature of PA and a narrower temperature range in which the crystallization process occurs) is achieved in the case of PA with a higher viscosity.
\end{abstract}

Keywords: nanocomposites, viscosity and elasticity ratios, PLA, shear-induced crystallization, PA droplets

\section{Introduction}

Due to the surge of recent regulations posing abrupt limits on the consumption of conventional plastics, the interest to develop eco-friendly biocomposites has been increased [1]. Great attempts are made to replace inorganic fillers with either natural fibers $[2,3]$, e.g. nanofibrillated cellulose [4], or renewable polymeric reinforcers $[5,6]$. The composites, reinforced by natural fibers, mainly suffer from poor interfacial adhesion and dispersion. Surface modification is among a few techniques practiced to prevent the agglomeration of natural nanoparticles [7].

All-polymeric nanocomposites that are formed by the in-situ conversion of biopolymer blends are developed to overcome the drawbacks. This concerns better dispersion and improved structure of a minor polymeric component developed during the process within the context of a matrix.

The mechanical and physical properties of all-polymeric composites rely exceptionally on the morphology of extruded immiscible blends. Depending on the blending conditions, various morphologies can be generated, for example, hybrid shish-kebab structures, co-continuous intertwined structures, discontinuous or continuous fibers/matrix as well as fiber network/ matrix ones [8-11]. Polymeric composites of the fibrillar structure are preferred over the blends with droplet morphology suffering from poor inter-phase boundaries. Good distribution of in-situ generated polymeric fibrils and their improved interface with the matrix, as well as the oriented molecular chains within generated micro/nanofibers of high aspect

${ }^{*}$ Corresponding author, e-mail: wozniak@cbmm.lodz.pl (C) BME-PT 
ratio, all lead to increased modulus and strength of the nanofibrillar polymeric composites $[12,13]$.

Whereas the incorporation of ready-made biopolymer fibers into biopolymer matrices still struggles, in-situ production of nanofibrillar biocomposites has been progressed so far applicable to industries. In the micro-injection process, a stable fibrous morphology is realized, implementing high shear rates. This approach is quite promising; however, it remains a challenge for conventional injection molding [14]. A multi-stage method comprising melt mixing, fibrillization, and isotropization eases in-situ formation of fibrillar morphology for a number of polymer pairs such as PLA/PBS [15], TPU/PLA [16], PLA/PCL [14], thermoplastic starch/PLA [17], PLA/PGA [18], PLA/PA [19]. However, the formation of randomly oriented fibrils is challenged for high concentrations of minor components [20]. Recently a new single-stage approach was proposed based on simultaneous formation and stabilization of polymer fibers directly at the stage of extrusion [15]. The nanofibers are solidified by virtue of shearinduced crystallization at a higher temperature without a subsequent cooling [21].

Despite unprecedented improvements in ductility and rigidity of the nanocomposites, in-situ formation and stabilization of polymeric nanofibers within the context of another biopolymer remains unsettled. The process is determined by rheological characteristics and the interfacial interaction of the components. Nonetheless, the concentration of minor components along with the capillary number (shear stress over interfacial tension) has been reported to play key roles in controlling the morphology $[22,23]$. In situ transformation of dispersed immiscible droplets (micro- or nano) into nanofibers under the action of shear forces should be explored to illuminate further the effects of interfacial interaction, viscoelasticity, and shear-induced crystallization.

The influence of viscoelasticity on the formation of nanofibrous morphology is mainly characterized by viscosity and elasticity ratios (dispersed component/ matrix), $K$ and $K^{\prime}$. Critical values of these parameters in the range of $0.5-10$ are reported [24]. However, the absolute values for affine deformation of viscoelastic droplets to nanofibers should be determined by the selected polymer pairs. Additional studies are also required to comprehend the evolution of generated nanofibers over lower values of $K$ and $K^{\prime}$, i.e., $0.1-0.5[19]$. The effect of viscoelasticity within the shear flow field could be challenged by the interfacial tension. The addition of compatibilizer would enhance the stress transfer to the extent that dispersed polymer could deform into elongated threads and fibers. Howbeit, this may impede the coalescence of dispersed droplets to form fibrils with a high aspect ratio. Therefore, the contribution over a wide range of viscosity ratios should be explored in detail $[25,26]$. The final aspect ratio depends on the stabilization of the fiber prior to retraction or breaking up. This may be achieved through improving the relaxation time or inducing crystallization of elongated thread at higher temperatures. The stabilization phenomenon is contingent on crystallization kinetics of the minor component [27].

This study applies the concept of in-situ generation of all-polymer nanocomposites by shear-induced crystallization to a range of PLA-PA blends. The rheology of biodegradable PLA and bio-based PA as the minor component are studied prior to the in-situ generation of nanocomposites. Precise viscoelastic characterization of the pairs at the processing temperature and shear rate is crucial for succeeding in the in-situ formation of the nanofibres network within the matrix. The rheological properties of PLA in the processing temperature range at customary shear rates are regulated by extending and branching the PLA's molecules. The pairs are chosen in a way that crystallization of PA is shear sensitive, and its melting temperature is higher than the softening (or melting) temperature of PLA. In order to stabilize the resulting nanofibrillar morphology in the flow and prevent undesired relaxation and breaking-up processes, an immediate solidification due to shear-induced crystallization for minor component polymers will be applied as a technique.

\section{Experimental}

\subsection{Materials}

Two commercial grades of PLA 4060D and PLA 3251D, supplied by NatureWorks LLC, were used as the matrices. The grades are biodegradable polylactide with the same density of $1.24 \mathrm{~g} \mathrm{~cm}^{3}$, and respective $M_{\mathrm{w}}$ of 120000 and $77000 \mathrm{~g} \cdot \mathrm{mol}^{-1}$. PLA ${ }_{\mathrm{HV}}$ and PLA - LV are assigned for PLA 4060D and PLA $3251 \mathrm{D}$, respectively, where HV indicates high viscosity, and LV represents low viscosity. Two fully biobased grades of polyamide (PA) with the trade name Vestamid Terra DS16 and DS18, supplied by Evonik Industries, were used to produce the composites. PA 
DS18 and PA DS16 are designated by PA $_{-H V}$ and PA $_{-L V}$, respectively. The monomers for the synthesis of both grades are derived from castor oil and show a melting point at $200^{\circ} \mathrm{C}$. Joncryl ADR 4400 , a polymeric chain extender with a medium epoxy equivalent weight, was donated by BASF Corporation and used to improve both the viscoelasticity of PLA and its interaction with PA.

\subsection{Sample preparation}

Blends and in-situ generated nanocomposites of PLA-PA were prepared following the procedure described earlier that included blending and shearing of blends to allow the formation of nanofibers and their shear-induced crystallization [15]. For the preparation of compatibilized blends, Joncryl was mixed with PLA and PA (both components were dried for $8 \mathrm{~h}$ at $60^{\circ} \mathrm{C}$ ) in the course of the twin-screw extruder where the temperature zones were set increasingly from 200 to $230^{\circ} \mathrm{C}$. The melt blends containing 1 , 2, and $4 \mathrm{wt} \%$ of Joncryl, $0.2 \mathrm{wt} \%$ of Irganox 1010 for prevention of the thermo-oxidative degradation and $0.2 \mathrm{wt} \%$ of metal deactivator Irganox MD $1024 \mathrm{U}$ for additional deactivation of catalysts were prepared using a co-rotating twin-screw extruder $2 \times 20 / 40$ D EHP (Zamak Mercator) operating at $120 \mathrm{rpm}$. In-situ conversion of blends was performed within a single-screw extruder with a temperature gradient descended from $230{ }^{\circ} \mathrm{C}$ (feed section) to $175^{\circ} \mathrm{C}$ (slit die). This additional processing was facilitated using the single-screw extruder (PlastiCorder PLV 151, Brabender; $D=19.5 \mathrm{~mm}, L / D=$ 25 , and $20 \mathrm{rpm}$ ) equipped with the $12 \mathrm{~mm}$ wide, $0.8 \mathrm{~mm}$ thick and $100 \mathrm{~mm}$ long slit die. The temperature of zones was specifically set to induce the crystallization of the sheared and deformed minor polymer component (i.e., PA) during the process. The extruder was equipped with a slit-die to increase the residence time. In order to study the effect of viscoelasticity on the generated nanocomposites, PLA was initially modified through melt mixing with the chain extender prior to the aforementioned extrusions, designated as PLA-J.

\subsection{Characterization}

Tensile properties of neat PLA, its blend, and in-situ generated composite were measured in Instron-5582 (Universal Testing Machine) at a strain rate of $5 \% \cdot \mathrm{min}^{-1}$, according to ISO 527-2. The tensile impact strength was determined in Resil-5.5 (Instrumented
Impact Tester) as per ISO 8256. Specimens with a gauge length of $25 \mathrm{~mm}$ and a width of $3 \mathrm{~mm}$ were struck by the hammer with a speed of $2.9 \mathrm{~m} \cdot \mathrm{s}^{-1}$ and energy of $1 \mathrm{~J}$. Seven specimens were tested for each sample at room temperature.

The morphology of blends and composites, cryogenically fractured along the extrusion direction and coated with gold, was investigated with JEOL JSM$5500 \mathrm{LV}$ scanning electron microscope. The in-situ generated nanofibers of PA were exposed to the SEM subsequent to the enzymatic selective etching of PLA proposed by $\mathrm{He}$ et al. [28].

2-D WAXS images were registered with a flat X-ray camera equipped with imaging plates (Fuji) and coupled to $\mathrm{Cu} \mathrm{K} \alpha$ source (sealed tube operating at $30 \mathrm{kV}$ and $50 \mathrm{~mA}$, Philips).

The rheological behavior of the materials was examined using a strain-controlled rotational rheometer (ARES LS2, TA Instruments). Steady-state shear measurements were executed to investigate the viscosity-elasticity dependencies of frequency. Samples were tested using cone-plate geometry with a cone angle of $0.1 \mathrm{rad}$ and a gap distance of $0.046 \mathrm{~mm}$. Disk-shaped samples with a diameter of $25 \mathrm{~mm}$ were cut out from extruded tapes and hot-pressed specimens. The frequency sweep tests were performed in the range from 0.1 to $400 \mathrm{rad} \cdot \mathrm{sec}^{-1}$.

Shear-induced crystallization of PA was scrutinized in the Linkam CSS450 (Optical Shearing System, Surrey, UK), as described in our other paper [11]. Films of PA were positioned between two heated glass stages undergoing subsequent treatment under a nitrogen flow: (1) heating $\left(30^{\circ} \mathrm{C} \cdot \mathrm{min}^{-1}\right)$ to $60^{\circ} \mathrm{C}$ above the melting point, (2) holding for $5 \mathrm{~min}$ to ensure complete melting, (3) cooling down $\left(10^{\circ} \mathrm{C} \cdot \mathrm{min}^{-1}\right)$ with simultaneous shearing at rates $100-400 \mathrm{sec}^{-1}$.

\section{Results and discussion}

\subsection{Role of interfacial interaction}

Figure 1 shows the droplet-matrix morphology of the fractured surface of PLA $\mathrm{LV}_{\mathrm{LV}} / \mathrm{PA}_{-\mathrm{HV}}$ blends with and without Joncryl compatibilizer. It is seen that with increasing the concentration of dispersed $\mathrm{PA}_{-\mathrm{HV}}$ from 5 to $40 \mathrm{wt} \%$, the pairs are immiscible and demonstrate droplets morphology. In the case of uncompatibilized PLA ${ }_{\mathrm{LV}} / \mathrm{PA}_{\mathrm{HV}}$ blend the average particle size $(D)$, referred to as droplet diameter, increases as the content of PA-HV dispersed component increases ranging from $2 \mu \mathrm{m}$ for PPLA $_{-\mathrm{LV}} / \mathrm{PA}_{-\mathrm{HV}}(95 / 5)$ up to $6 \mu \mathrm{m}$ for $\mathrm{PLA}_{-\mathrm{LV}} / \mathrm{PA}_{-\mathrm{HV}}(60 / 40)$ (Figure 1a-1d). The 


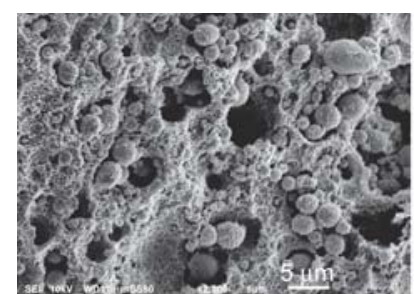

a)

$D=2.0 \mu \mathrm{m}$

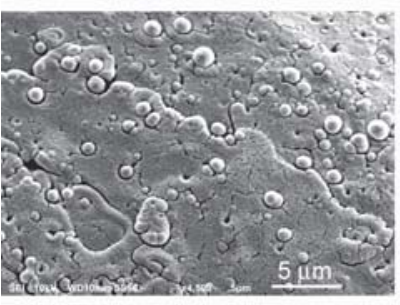

e)

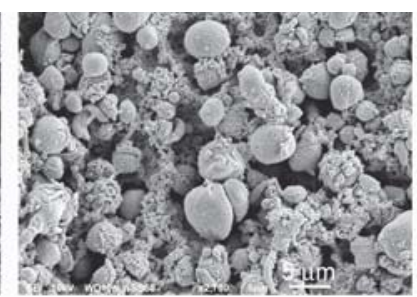

b)

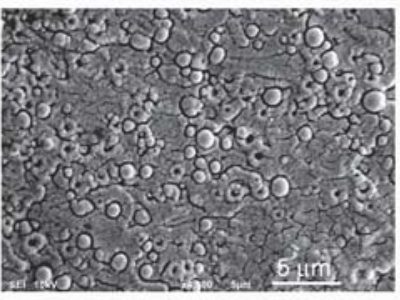

$D=1.1 \mu \mathrm{m}$

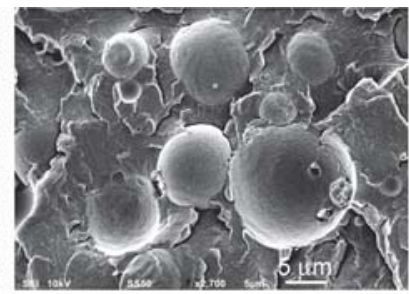

c)

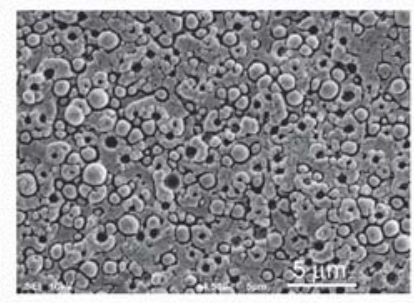

g)

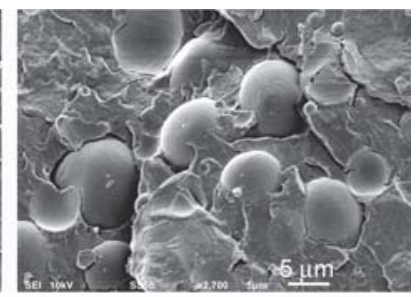

d)

$D=6.0 \mu \mathrm{m}$

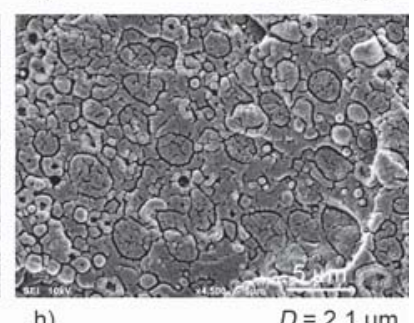

h)

$D=2.1 \mu \mathrm{m}$

Figure 1. SEM images of PLA_LV/PA_HV blends prepared without $(\mathrm{a}-\mathrm{d})$ and with $(\mathrm{e}-\mathrm{h})$ adding $2 \mathrm{wt} \%$ of compatibilizer Joncryl. Samples were prepared by dispersing $(\mathrm{a}, \mathrm{e}) 5$, (b, f) 10, (c, g) 20, and (d, h) $40 \mathrm{wt} \%$ of PA_HV within PLA_LV.

micron size of the dispersed component is attributed to a higher possibility of droplet coalescence during blending and indicates a low interfacial interaction between the $\mathrm{PA}_{-\mathrm{HV}}$ and PLA $\mathrm{LVV}_{-\mathrm{V}}$ components, which hinders the effective transfer of applied stress from the matrix to the dispersed component. Moreover, the resulting morphology suggests that in the presence of a few percent of the dispersed component, aggregation of the particles via coalescence is favored over breaking-up due to unfavorable viscosity ratio.

For PLA ${ }_{-\mathrm{LV}} / \mathrm{PA}_{-\mathrm{HV}}$ blends with $2 \mathrm{wt} \%$ Joncryl the average particle size decreases by $50-70 \%$ and is respectively from 1.0 to $1.1,1.3$, and $2.1 \mu \mathrm{m}$ for 5,10 , 20 and $40 \mathrm{wt} \%$ of PA (Figure $1 \mathrm{e}-1 \mathrm{~h}$ ). The formation of a finer dispersed component is also accompanied by a more homogeneous distribution of PA particles. A significant increase in elasticity of the compatibilized blend as compared to uncompatibilized ones (Figure 2) well demonstrates the enhanced interfacial interaction between the matrix and dispersed droplets in the presence of the compatibilizer.

The frequency dependences of complex viscosity $\left(\eta^{*}\right)$ and tan delta are plotted in Figure 2a, 2b for neat PLA $_{\mathrm{LV}}$, and the PLA $\mathrm{LV}_{\mathrm{LV}} / \mathrm{PA}_{\mathrm{HV}}(95 / 5)$ blends compatibilized with 1, 2, and $4 \mathrm{wt} \%$ of Joncryl. All curves are characterized by a typical decrease of viscosity as the frequency increases. It is seen that the addition of $1 \mathrm{wt} \%$ of Joncryl to the blend doesn't increase the viscosity considerably, which well complies with the obtained brittleness, discussed previously for this composition. The meaningful decrease of the $\tan \delta$, especially at $10 \mathrm{~Hz}$, proves the improved elasticity of the blend. The introduction of further compatibilizer increases the complex viscosity up to two orders of magnitudes and decreases the tan delta to around unity. The least tan delta value is observed for the blend compatibilized with $4 \mathrm{wt} \%$ of Joncryl. This significant increase in elasticity of the blend well demonstrates the enhanced interfacial interaction between the matrix and dispersed droplets.

Treatment of PLA ${ }_{L V}$ with Joncryl modifies its molecular structure and results in improved melt strength. Figure $2 \mathrm{c}$ plots the complex viscosity as a function of temperature for neat PLA $-\mathrm{LV}$ and treated samples via 1,2, and $4 \mathrm{wt} \%$ of Joncryl. The carboxyl end groups of PLA could potentially react with the epoxy groups in the chain extender, and this led to the remarkable increase in complex viscosity.

An increase in the concentration of the compatibilizer leads to a further decrease in the average size of PA inclusions (Figure 3a-3c). At $4 \mathrm{wt} \%$ Joncryl, $\mathrm{PA}_{-\mathrm{HV}}$ micro-droplets develop to particles with an average size of $880 \mathrm{~nm}$ as a consequence of efficient stress transfer from the matrix to the dispersed component during mixing.

As proven by the viscometry results (Figure 4), for $\mathrm{PLA}_{-\mathrm{LV}} / \mathrm{PA}_{-\mathrm{HV}}$ blend the values of viscosity and elasticity ratios, $K$ and $K^{\prime}$, are in the range of $(10$; $100)$ within the process temperature range of 190 to $230^{\circ} \mathrm{C}$, which is far from the optimal values of $(0.1$; 10). The substantial difference in the viscosities demonstrates that the viscous force is insufficient to overcome the cohesive strength of the $\mathrm{PA}_{-\mathrm{HV}}$, failing from affine deformation. In addition, remarkable higher elasticity of $\mathrm{PA}_{-\mathrm{HV}}$ contributes to the obtained 

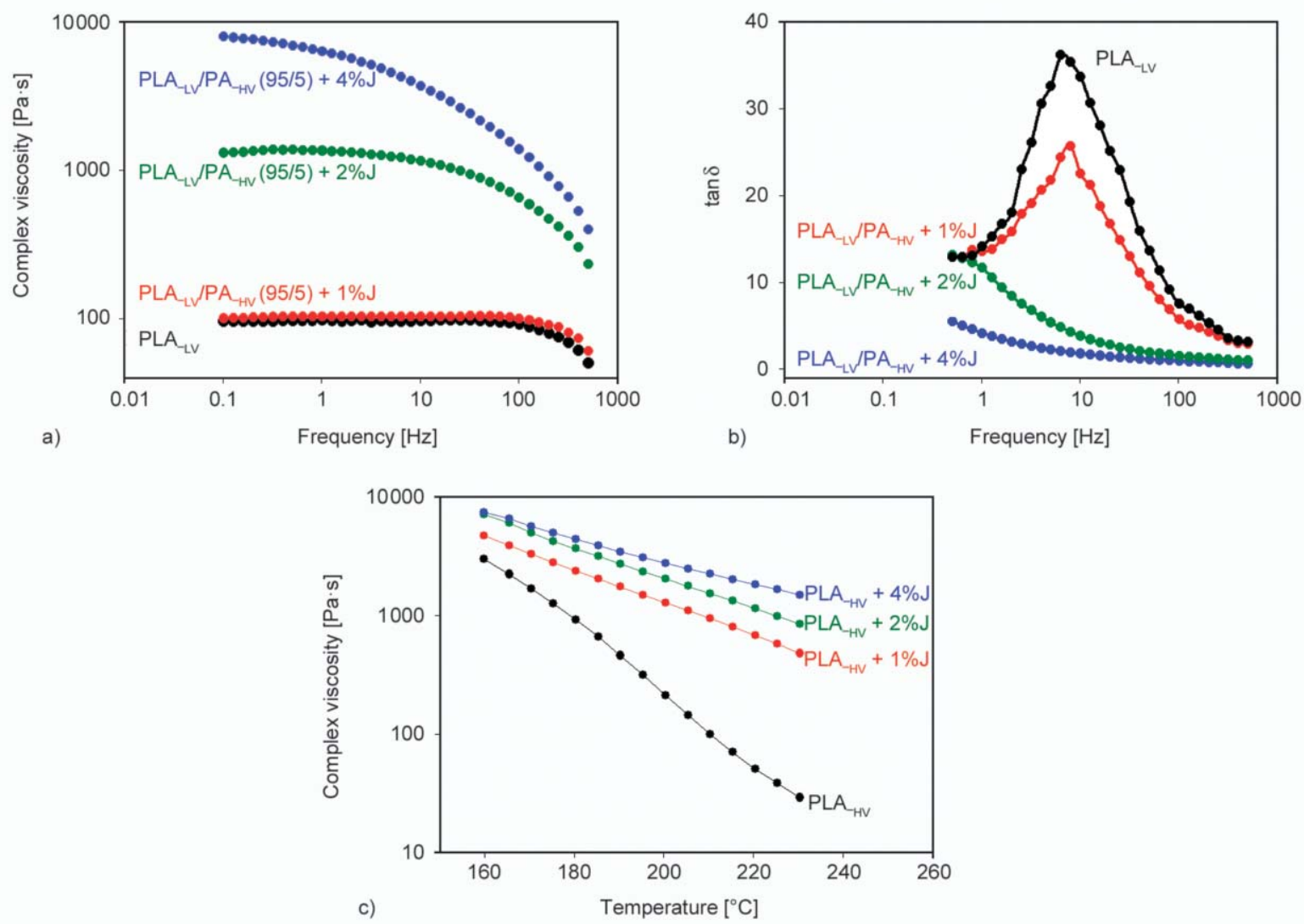

Figure 2. Complex viscosity (a) and $\tan \delta$ (b) of neat PLA $-\mathrm{LV}$ and compatibilized blends as a function of frequency, measured at $180^{\circ} \mathrm{C}$. Complex viscosity as a function of temperature for neat PLA $-\mathrm{LV}$ and treated samples by adding 1,2 , and $4 \mathrm{wt} \%$ of Joncryl (c).

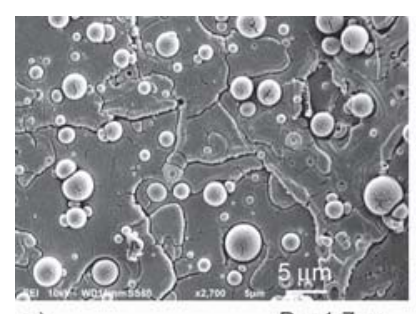

a)

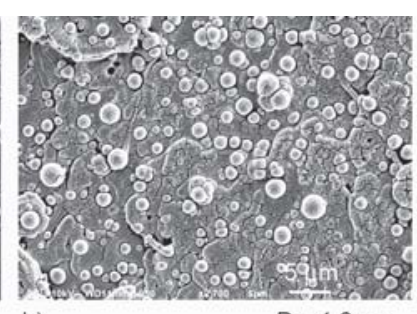

b)

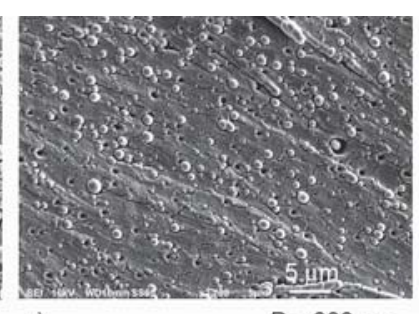

$D=880 \mathrm{~nm}$

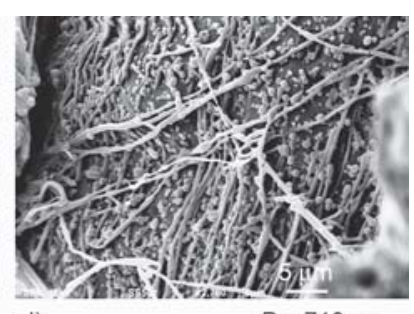

d)

$D=710 \mathrm{~nm}$

Figure 3. SEM images of PLA $-\mathrm{LV} / \mathrm{PA}_{\mathrm{HV}}$ (95/5) compatibilized by (a) 1, (b) 2, (c) and (d) $4 \mathrm{wt} \%$ of Joncryl. (a-c) - blends, (d) - in-situ generated composite.

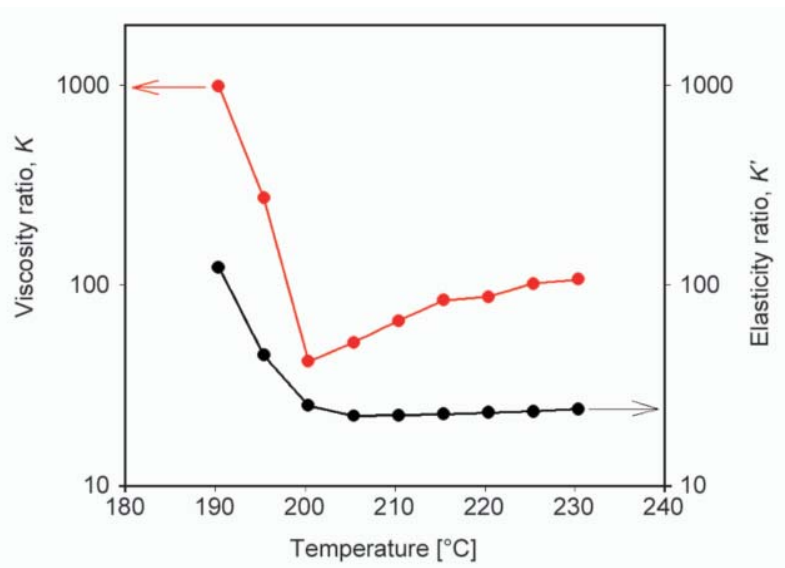

Figure 4. Viscosity and elasticity ratios, $K$ and $K^{\prime}$, measured for $\mathrm{PA}_{\mathrm{HV}}$ and PLA $-\mathrm{LV}$ as a function of temperature. droplet structure by impeding the continuous elongation of $\mathrm{PA}_{-\mathrm{HV}}$ droplets into threads. The introduction of a compatibilizer does not seem to alter the $K$ and $K^{\prime}$ coefficients significantly. As a result, shear deformation does not lead to the formation of a completely fibrillar structure, and only a partial replacement of droplets by fibrils is observed (Figure 3d). Thus, an increase in the concentration of the compatibilizer provides an increase in the interfacial interaction and the formation of a finely dispersed droplet morphology associated with this, but the presence of the compatibilizer in PLA-LV $/ \mathrm{PA}_{-\mathrm{HV}}$ blends does not cause a transition from droplet to fibrillar morphology during shear deformation. According to [29-34], 
improved interfacial interaction can lead to micro or nanofibril formation. However, the interfacial interaction is not a critical parameter for the droplet to fiber transition in the dispersed component; it just can facilitate [29] or even depress [30-34] this process.

\subsection{Effect of viscoelasticity}

Although there are many factors affecting the morphology of dispersed components in the blend, which include processing parameters, composition etc., it is the viscosity and elasticity ratios that are one of the most important parameters governing the transition of droplets to fibers. It is known that the higher viscosity and elasticity of the matrix, the higher degree of deformation and extension of the dispersed droplets, and the lower elasticity of dispersed polymer the stronger stabilizing effect, which restrains droplet from breaking. As a result, lower viscosity and elasticity ratios favor the formation of fibrillar morphology. Thus, the PLA-chain extender blend was used in order to increase the viscosity and elasticity of PLA. Moreover, this was facilitated by means of $\mathrm{PA}_{-\mathrm{LV}}$ with lower viscosity and PLA ${ }_{-\mathrm{HV}}$ possessing higher viscosity

Figure 5 presents the viscosity and elasticity ratio for $\mathrm{PA}_{-\mathrm{HV}} / \mathrm{PLA}_{-\mathrm{LV}}, \mathrm{PA}_{-\mathrm{LV}} / \mathrm{PLA}_{-\mathrm{HV}}$, and PA $\mathrm{LV}_{\mathrm{LV}} / \mathrm{PLA}_{-\mathrm{HV}} \mathrm{J}$ pairs within the process temperature range of 190 to $230{ }^{\circ} \mathrm{C}$. It is seen that the $\mathrm{PA}_{-\mathrm{LV}} / \mathrm{PLA}_{-\mathrm{HV}}$ pair possesses 10 times lower values for viscosity ratio compared to the $\mathrm{PA}_{-\mathrm{HV}} / \mathrm{PLA}_{-\mathrm{LV}}$. Besides, the elasticity ratio exhibits comparatively lower values. Unlike the addition of $1 \mathrm{wt}$. \% Joncryl as a compatibilizer, using it as a chain extender to PLA effectively enhances the viscoelasticity and leads to the viscosity ratio below unity for the whole process temperature. Meantime, a significant decrease in the elasticity ratio is observed where it drops down to below 5 for the specified temperature range. Treatment of the matrix with $4 \mathrm{wt} \%$ of the chain extender lowers the viscosity ratio to 0.15 . However, the elasticity ratio seems to saturate at around 2 for Joncryl concentration of 2 and $4 \mathrm{wt} \%$.

Figure 6 demonstrates the effect of viscoelasticity on the the PA $-\mathrm{LV}$ fibrillar morphology. The $\mathrm{PA}_{-\mathrm{LV}}$ nanofibers were revealed after mild etching the matrix from the in-situ generated composites.

For a PLA ${ }_{-\mathrm{HV}} / \mathrm{PA}_{-\mathrm{LV}}$ blend (Figure 6a), a decrease in viscosity ratio to 2.8 and elasticity ratio to 15 contributes to the destabilization of PA droplets under shear deformation, and the formation of the fibrils with a diameter varied from 340 to $910 \mathrm{~nm}$. Lower values of viscosity and elasticity ratios, 0.4 and 3 , respectively, in the case of $\mathrm{PA}_{-\mathrm{LV}} / \mathrm{PLA}_{-\mathrm{HV}}-1 \% \mathrm{~J}$, cause the formation of thinner fibrils with diameters in the range of 180-740 $\mathrm{nm}$ (Figure 6b). Meanwhile, nanofibers tend to be more uniform.

A further decrease in viscosity ratio to 0.3 and elasticity ratio to 2 for $\mathrm{PA}_{-\mathrm{LV}} / \mathrm{PLA}_{-\mathrm{HV}} 2 \% \mathrm{~J}$, is accompanied by an even greater thinning of fibrils varying from 110 to $330 \mathrm{~nm}$. It should be noted that in this case, a physically entangled nanofibrous network started to form (Figure 6c). The latter may be due to the fact that thinner and longer nanofibrils increase the probability of physical links formation between them.

However, as the viscosity ratio approaches 0.15 with a constant elasticity ratio of about 2 for $\mathrm{PA}_{-\mathrm{LV}} /$ PLA $_{-H V}-4 \% \mathrm{~J}$, nanofibers start to break up to tiny nanodroplets. Figure $4 \mathrm{~d}$ depicts that newly formed sub-particles possess a diameter varied from 140 to

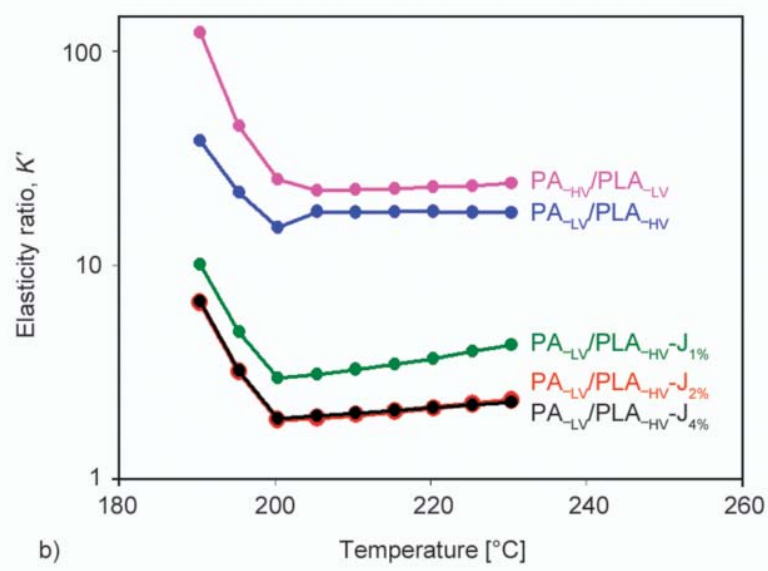

Figure 5. Viscosity (a) and elasticity ratios (b) of PA to PLA, $K$ and $K^{\prime}$, as a function of temperature, measured at the frequency of $10 \mathrm{rad} / \mathrm{s}$. 


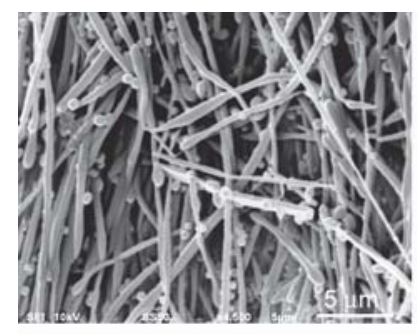

a)

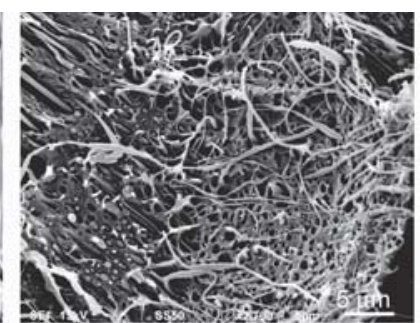

b)

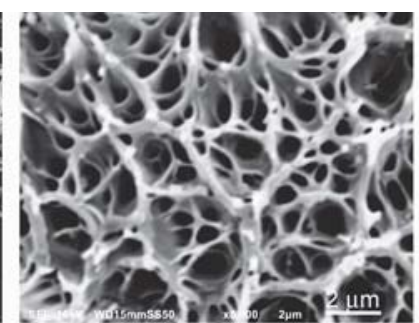

Network

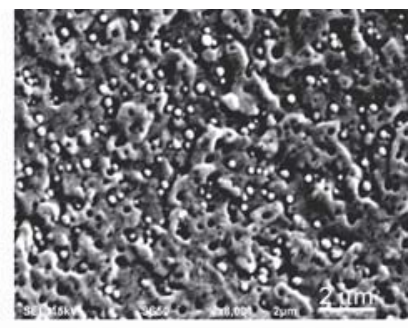

d)

Droplets

Figure 6. SEM images of PLA ${ }_{H V} / \mathrm{PA}_{\mathrm{LV}}(95 / 5)$ in-situ generated composites. The concentration of Joncryl, respectively, is (a) 0 , (b) 1 , (c) 2 and (d) $4 \% . L / D$ is the characteristic ratio of fibrils length to their thickness (calculated on the basis of the visible part of fibrils, and therefore may be slightly lower than the actual values).

$430 \mathrm{~nm}$. It seems that there is a certain critical thickness of nanofibrils, below which the flow of molten $\mathrm{PA}_{-\mathrm{LV}}$ inclusions becomes unstable because of the excessively high stress on the interface. Furthermore, the elasticity ratio of approximately 2 provides a certain stress relaxation during the growth of interfacial disturbances, which leads to the creation of finer nanodroplets upon breakup.

Figure 7 demonstrates existing instabilities and efficient stress transfer at the interface that provoke nanofibers breaking-up into sub-nanodroplets. It is seen that as PA fiber's diameter decreases to around $250 \mathrm{~nm}$, the interfacial tension emulates the applied shear stress and tends to fragment the fiber into subparticles. These so-called Rayleigh disturbances are accelerated by the small viscosity ratio of around 0.15 . As a result, $\mathrm{PA}_{\mathrm{LV}}$ elongated fibers may break up drop-by-drop from the ends through so-called endpinching (Figure 7a) or may disintegrate via fracture mode to form micro and nanofibers (Figure 7b). Once the shearing is halted, the fibers tend to return to a more stable and equilibrated state by relaxing back to initial shape (Figure 7c). However, rapid solidification induced by shearing could retard the retraction imposed by interfacial tension forces.

Thus, there are upper and lower bounds for viscosity and elasticity ratios providing efficient droplets to fibers transitions. Above the upper boundary, the viscosity of the polymer matrix is insufficient to overcome cohesive bonds, and the high viscosity of the dispersed component tends to reverse the elongation of droplets into threads. Below the lower boundary, formed very thin nanofibrils become unstable, and their flow is accompanied by breakingup into sub-nanodroplets.

\subsection{Effect of shear-induced crystallization}

It is known that the viscosity and elasticity ratios can significantly decrease with an increase in shear rate [19]. Therefore, at high shear rates, both of these parameters may decrease below the upper boundary and, accordingly, droplets to fibers transition will occur. The critical shear rate necessary to form the fibrillar morphology is determined by the selected pair of polymers [19]. At the same time, it can be expected that a high shear rate can determine not only the formation of fibers but also their stabilization in the flow. This can be achieved by shear-induced crystallization. In this case, the crystallization of the polymer will take place at temperatures significantly higher than its non-isothermal crystallization temperature and will contribute to the suppression of relaxation processes associated with the cooling of fibrils and their transformation into a crystalline state. Thus, shear-induced crystallization can be considered as an alternative process to the selection of polymer inclusions with long relaxation time, and its effectiveness is confirmed in Section 3.2.
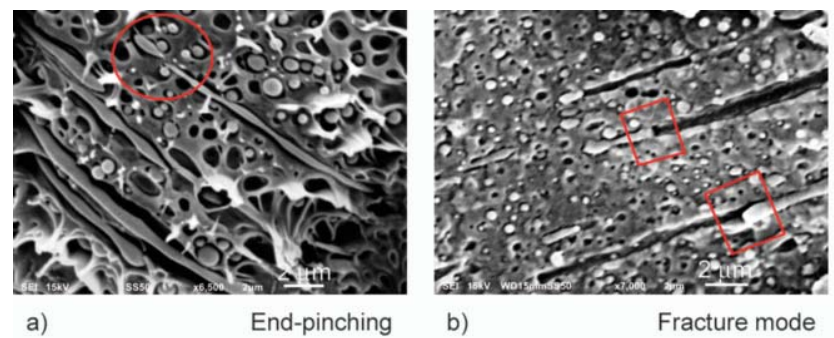

b)

Fracture mode

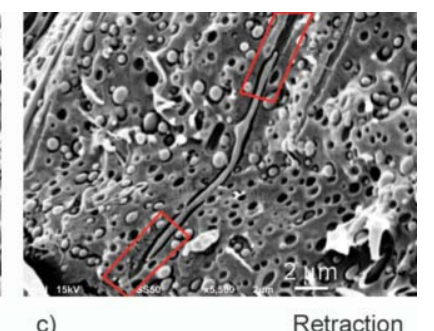

c)

Retraction

Figure 7. SEM images of $\mathrm{PA}_{\mathrm{LV}}$ nanofibers undergoing end pitching (a), breakup (b), and retraction (c) at the composition of PLA ${ }_{H V} / \mathrm{PA}-\mathrm{LV}(95 / 5)$. 
Figure 8 shows the shear rate $\gamma$ dependences of the crystallization temperature $T_{\mathrm{C}}, \Delta T_{1 / 2}$, and $\Delta T$ for $\mathrm{PA}_{\mathrm{HV}}$ and $\mathrm{PA}_{-\mathrm{LV}}$. The term $\Delta T$ represents the temperature range over which full transition from the molten to crystalline state occurs, while $\Delta T_{1 / 2}$ regards $50 \%$ of the conversion. It is found that once the samples are sheared during cooling, the conversion of molten PA to crystals could initiate and grow at a higher and narrower range of temperatures. These well demonstrate remarkable shifts in the crystallization temperature of PA, induced via the applied shear rates. A higher effect is achieved in the case of PA with a higher viscosity. Indeed, for $\mathrm{PA}_{-\mathrm{HV}}$ the crystallization temperature is raised from $153{ }^{\circ} \mathrm{C}$ for the non-sheared state to $191^{\circ} \mathrm{C}$ upon applying shear with the rate $300 \mathrm{sec}^{-1}$. Moreover, the inception of crystallization for $\mathrm{PA}_{-\mathrm{HV}}$ is shifted from 180 to $210^{\circ} \mathrm{C}$, and the crystallization is accomplished $(\Delta T)$ over a shorter range of $25^{\circ} \mathrm{C}$ rather than $55^{\circ} \mathrm{C}$ for nonsheared $\mathrm{PA}_{-\mathrm{HV}}$. In the case of $\mathrm{PA}_{-\mathrm{LV}}$, a higher shift in $T_{\mathrm{C}}$ is observed by shearing at $200 \mathrm{sec}^{-1}$ since PA molten chains may orient easily to crystallize. However, the low viscosity of $\mathrm{PA}_{-\mathrm{LV}}$ accompanied by insufficient melt flow strength and non-laminar flow due to Taylor vortices challenged the realization of crystallization kinetic at the shear rate of $300 \mathrm{sec}^{-1}$. Despite PA $\mathrm{HV}_{\mathrm{HV}}$, which crystallization occurs within a narrower temperature range, $\Delta T$ remains almost constant for $\mathrm{PA}_{-\mathrm{LV}}$ while $\Delta T_{1 / 2}$ decreases considerably. It seems that the orientational memory of chains is preserved over a small time gap between cessation of shearing and the onset of crystallization, leading to a decrease of $\Delta T_{1 / 2}$. Once $50 \%$ of conversion is accomplished, the loss of conformation memory retards the growth of nuclei. It is suggested that for $\mathrm{PA}_{\mathrm{LV}}$, shear stress affects preferably the nucleation rate rather than the growth of crystals. Anyhow, the size of spherulites in sheared samples is too small to be exactly resolved in polarized light micrographs.

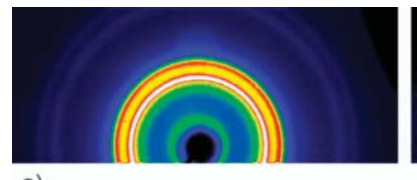

a)

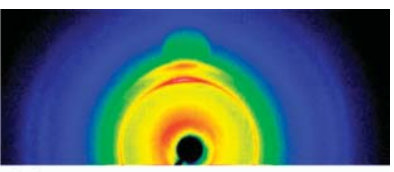

b)

Figure 9. 2-D WAXS patterns of PA-HV non-isothermally crystallized without shear (a) and upon applying shear with the rate $300 \mathrm{~s}^{-1}$ (b).

It should be noted that shear-induced crystallization of PA is accompanied by the formation of the molecular orientation, which is confirmed by the 2D WAXS data (Figure 9). The latter is important to get a true reinforcing component since its properties differ from those of the bulk material [35].

\subsection{Mechanical properties}

The transformation from micro to nanodroplet structure, as well as the formation of fibrillar morphology of dispersed polymer component, causes a significant change in the mechanical properties of PLA-PA blends. Figure 10a shows the stress-strain dependencies determined by uniaxial tensile test for $\mathrm{PLA}_{\mathrm{LV}} /$ PA ${ }_{H V}(95 / 5)$ neat and compatibilized blends as well as in-situ generated composite. It is seen that the introduction of $4 \mathrm{wt} \%$ compatibilizer, which enhances the formation of nanodroplet morphology of dispersed polymer component, leads to a significant improvement in ductility of the blend. Table 1 demonstrates that $\mathrm{PLA}_{-\mathrm{LV}} / \mathrm{PA}_{-\mathrm{HV}}+4 \% \mathrm{~J}$ blend breaks at a strain of 80 versus $2 \%$ for a neat $\mathrm{PLA}_{-\mathrm{LV}} / \mathrm{PA}_{-\mathrm{HV}}$ blend. Tensile impact strength increases from $55 \mathrm{~kJ} / \mathrm{m}^{2}$ for the blend

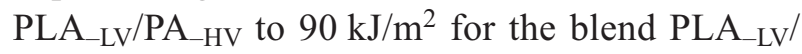
$\mathrm{PA}_{-\mathrm{HV}}+4 \% \mathrm{~J}$. Yield stress moderately increases from $43 \mathrm{MPa}$ for a neat blend to $47 \mathrm{MPa}$ for a compatibilized blend. At the same time, stress at break decreases from 43 to $34 \mathrm{MPa}$. Young modulus does not change with the introduction of a $4 \%$ compatibilizer.

In comparison to the blend, $\mathrm{PLA}_{-\mathrm{LV}} / \mathrm{PA}_{-\mathrm{HV}}+4 \% \mathrm{~J}$ composite with a partial fibrillar morphology renders

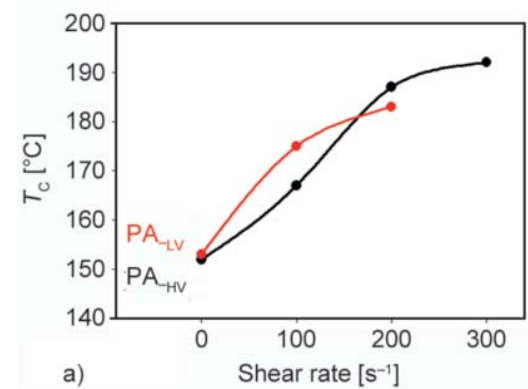

a)

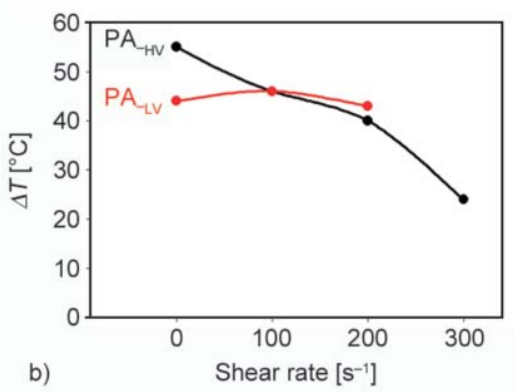

Figure 8. Shear rate dependences of $T_{\mathrm{C}}$ (a), $\Delta T$ (b), and $\Delta T_{1 / 2}$ (c) of PA $\mathrm{HV}_{\mathrm{HV}}$ and $\mathrm{PA}_{\mathrm{LV}}$, crystallized from melt. The samples were cooled down with simultaneous shearing at various shearing rates. 
Table 1. Mechanical properties of $\mathrm{PLA}_{\mathrm{LV}} / \mathrm{PA}_{\mathrm{HV}}(95 / 5)$ blends and composite.

\begin{tabular}{|c|c|c|c|c|c|c|}
\hline Material & Composition & $\begin{array}{l}\text { Young modulus } \\
\text { [GPa] }\end{array}$ & $\begin{array}{l}\text { Yield stress } \\
\text { [MPa] }\end{array}$ & $\begin{array}{c}\text { Strain at break } \\
{[\%]}\end{array}$ & $\begin{array}{l}\text { Stress at break } \\
{[\mathrm{MPa}]}\end{array}$ & $\begin{array}{l}\text { Tensile impact strength } \\
\qquad\left[\mathrm{kJ} / \mathrm{m}^{2}\right]\end{array}$ \\
\hline Blend & $\mathrm{PLA}_{-\mathrm{LV}} / \mathrm{PA}_{\mathrm{HV}}$ & 1.89 & 43.2 & 2 & 43.2 & 55 \\
\hline Blend & $\mathrm{PLA}_{-\mathrm{LV}} / \mathrm{PA}_{\mathrm{HV}}+1 \% \mathrm{~J}$ & 1.50 & 47.8 & 5 & 44.1 & 53 \\
\hline Blend & $\mathrm{PLA}_{-\mathrm{LV}} / \mathrm{PA}_{\mathrm{HV}}+2 \% \mathrm{~J}$ & 1.88 & 47.9 & 50 & 26.7 & 73 \\
\hline Blend & $\mathrm{PLA}_{-\mathrm{LV}} / \mathrm{PA}_{\mathrm{HV}}+4 \% \mathrm{~J}$ & 1.90 & 47.1 & 80 & 34.8 & 90 \\
\hline Composite & $\mathrm{PLA}_{-\mathrm{LV}} / \mathrm{PA}_{\mathrm{HV}}+4 \% \mathrm{~J}$ & 2.01 & 47.7 & 150 & 37.1 & 95 \\
\hline
\end{tabular}

Table 2 Mechanical properties of neat PLA ${ }_{\mathrm{HV}}$ and PA $\mathrm{LV}_{\mathrm{LV}}$ as well as the blends and composites of PLA $\mathrm{HV}_{\mathrm{HV}} / \mathrm{PA}_{\mathrm{LV}}(95 / 5)$.

\begin{tabular}{|c|c|c|c|c|c|c|}
\hline Material & Composition & $\begin{array}{l}\text { Young modulus } \\
\text { [GPa] }\end{array}$ & $\begin{array}{l}\text { Yield stress } \\
\text { [MPa] }\end{array}$ & $\begin{array}{c}\text { Strain at break } \\
{[\%]}\end{array}$ & $\begin{array}{c}\text { Stress at break } \\
\text { [MPa] }\end{array}$ & $\begin{array}{c}\text { Tensile impact strength } \\
{\left[\mathrm{kJ} / \mathbf{m}^{2}\right]}\end{array}$ \\
\hline Neat & $\mathrm{PLA}_{\mathrm{HV}}$ & 1.79 & 50.8 & 4 & 49.8 & 52 \\
\hline Neat & $\mathrm{PA}_{\mathrm{LV}}$ & 1.10 & 34.9 & 220 & 55.9 & 511 \\
\hline Blend & $\mathrm{PLA}_{\mathrm{HV}} / \mathrm{PA}_{\mathrm{LV}}$ & 1.80 & 37.4 & 102 & 33.4 & 58 \\
\hline Blend & $\mathrm{PLA}_{\mathrm{HV}^{-}} 1 \% \mathrm{~J} / \mathrm{PA}_{\mathrm{LV}}$ & 1.80 & 40.2 & 114 & 36.7 & 63 \\
\hline Blend & $\mathrm{PLA}_{-\mathrm{HV}}-2 \% \mathrm{~J} / \mathrm{PA}_{\mathrm{LV}}$ & 1.80 & 45.4 & 120 & 38.9 & 74 \\
\hline Blend & $\mathrm{PL}_{\mathrm{A}-\mathrm{H}} \mathrm{V}-4 \% \mathrm{~J} / \mathrm{P}_{\mathrm{A}-\mathrm{LV}}$ & 1.81 & 48.0 & 140 & 39.4 & 59 \\
\hline Composite & $\mathrm{PLA}_{\mathrm{HV}} / \mathrm{PA}_{\mathrm{LV}}$ & 1.95 & 43.6 & 200 & 35.7 & 60 \\
\hline Composite & $\mathrm{PLA}_{\mathrm{HV}^{-}} 1 \% \mathrm{~J} / \mathrm{PA}_{\mathrm{LV}}$ & 1.95 & 44.2 & 185 & 36.5 & 64 \\
\hline Composite & $\mathrm{PLA}_{-\mathrm{HV}}-2 \% \mathrm{~J} / \mathrm{PA}_{\mathrm{LV}}$ & 1.98 & 50.0 & 180 & 39.6 & 74 \\
\hline Composite & $\mathrm{PLA}_{\mathrm{HV}^{-}} 4 \% \mathrm{~J} / \mathrm{PA}_{-\mathrm{LV}}$ & 1.82 & 49.2 & 145 & 39.8 & 67 \\
\hline
\end{tabular}

remarkably higher values of $2.01 \mathrm{GPa}$ and $150 \%$ for Young modulus and strain at break, respectively. Subsequently, tensile impact strength increased slightly from 90 to $95 \mathrm{~kJ} / \mathrm{m}^{2}$.

The tensile results in Figure 10b differentiate the development of mechanical properties from high strength brittle $\mathrm{PLA}_{-\mathrm{HV}}$ to the ductile, tough $\mathrm{PA}_{-\mathrm{LV}}$ with lower yield stress. Compared to neat PLA ${ }_{-\mathrm{HV}}$ and $\mathrm{PA}_{-\mathrm{LV}}$, the in situ generated PLA $\mathrm{HV}_{-\mathrm{PA}} / \mathrm{PA}_{\mathrm{LV}}$ composite is characterized by the lowest stress at break value, but the highest Young modulus value (Table 2). The presence of randomly oriented nanofibers with a high average aspect ratio of 50, proved by SEM observations, causes the high value of elongation at break up to $200 \%$ for $\mathrm{PLA}_{\mathrm{HV}} / \mathrm{PA}_{\mathrm{LV}}$ composite comparable to neat PA. Such a significantly improved toughness arose from the fact that in-situ generated PA nanofibers could maintain the integrity of PLA and preserve its cohesion by damping the applied load. As shown earlier by us [11], the nanofibers retard the propagation of already initiated crazes by tufting the surfaces of crazes and prevent their growth and development into microcracks. Introduction of $2 \mathrm{wt} \%$ of chain extender modifies the elasticity of PLA and helps for the formation of a network of more oriented PA fibrils. Table 2 shows that $\mathrm{PLA}_{-\mathrm{HV}}-2 \% \mathrm{~J} / \mathrm{PA}-\mathrm{LV}$ composite with interconnected fibrous morphology compromises slightly lower strain
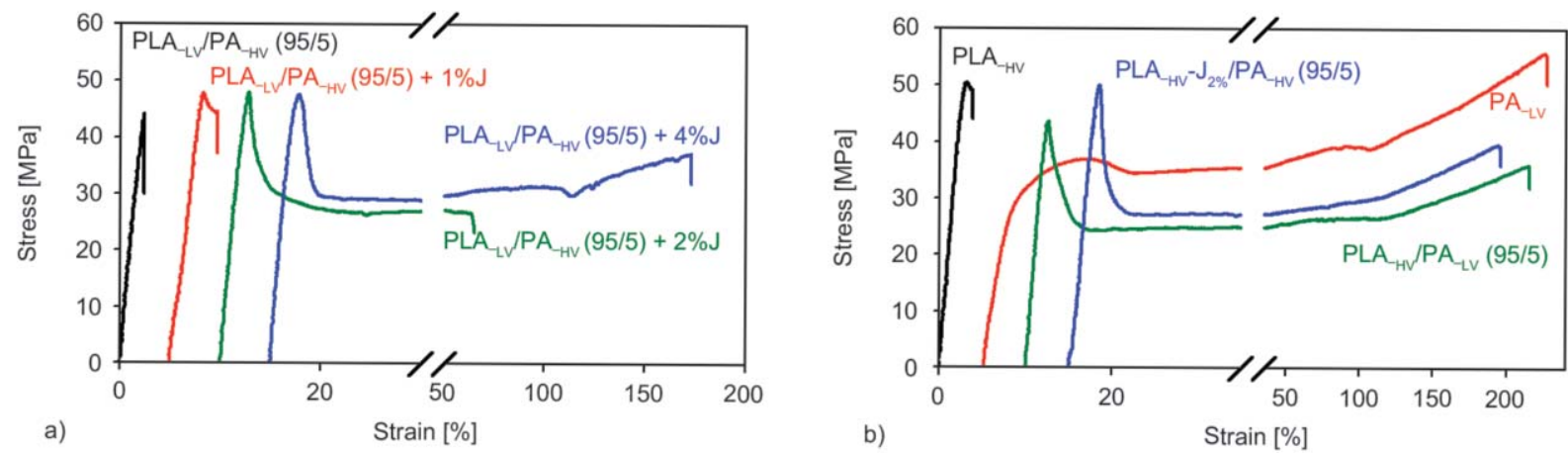

Figure 10. Stress-strain dependencies of (a) neat and compatibilized blends and an in-situ generated composite of $\mathrm{PLA}_{\mathrm{LV}} / \mathrm{PA}_{\mathrm{HV}}$, (b) PLA $\mathrm{PV}_{\mathrm{HV}} / \mathrm{PA}_{\mathrm{LV}}$ in-situ generated nanocomposites. The curves are shifted horizontally for clarity. 
at break but higher impact strength, compared to $\mathrm{PLA}_{-\mathrm{HV}} / \mathrm{PA}_{-\mathrm{LV}}$ composite with discontinuous fibers. Nevertheless, the strain at break of PLA $-\mathrm{HV}_{-} 2 \% \mathrm{~J} /$ $\mathrm{PA}_{\mathrm{LV}}$ nanocomposite is substantially high, i.e., $180 \%$. This is accompanied by the increase of yield stress approximately to the value for neat PLA, $50 \mathrm{MPa}$. The existence of a physically entangled network of thinner $\mathrm{PA}_{-\mathrm{LV}}$ nanofibers makes the main contribution to the improved tensile properties of nanocomposites.

\section{Conclusions}

In this study, viscosity and elasticity ratios $\left(K, K^{\prime}\right.$, as well as interfacial interaction, found to be major parameters dominating the morphology and mechanical properties of PLA-PA blends and in-situ generated nanocomposites. In order to widely vary the viscoelasticity of the forming systems, Joncryl ADR 4400 was used as a compatibilizer for PLA/PA blend and as a chain-extender for PLA matrix prior to blending with PA. Moreover, PLA and PA with different viscosities were also used. It was established that for PLA/PA, critical values of $K$ and $K^{\prime}$ providing efficient in situ fibrils formation are in the range of 2.8 0.3 and 15.0-2.0, respectively. Inside the above set intervals, as these parameters decrease, thinner and longer PA nanofibers form, and ultimately a network of nanofibrils is developed. In particular, the blend with $K=2.8$, and $K^{\prime}=15$ nanofibrils of PA are produced with a high aspect ratio of 50 and fibers diameter ranging from 340 to $910 \mathrm{~nm}$. Blend with $K$ and $K^{\prime}$ values of 0.4 and 3, alters the morphology of nanofibers with a higher aspect ratio of 64 and fibers diameter ranging from 180 to $740 \mathrm{~nm}$. Finally, for the blend with viscosity and elasticity ratios of 0.3 and 2 , respectively, a three-dimensional network of randomly oriented, entangled nanofibers (110 to $330 \mathrm{~nm}$ ) is achieved. Below the lower critical values i.e. $K<$ 0.3 and $K^{\prime}<2.0$, very thin PA nanofibrils are formed, less than $250 \mathrm{~nm}$, and are destabilized due to the excessively high stress on the interface and their flow is accompanied by breaking-up into sub-nanodroplets through end-pinching or fracture. Above the higher critical values of $K$ and $K^{\prime}$, the viscosity of the polymer matrix is insufficient to force the droplets to fibers transitions, and the presence of a compatibilizer can only lead to a partial formation of a fibrillar structure. The shear-induced crystallization allows the stabilization of PA nanofibers immediately under applying a high shear rate without subsequent cooling. It is shown that for PA with a higher viscosity, there is a more significant increase in the crystallization temperature and a narrower temperature range in which the crystallization process occurs, which is associated with a difference in melt flow strength and orientational memory affecting the formation of nucleation sites.

The effect of the abovementioned processes on the formation and stabilization of PA nanofibers is illustrated in Figure 11.

Mechanical tests demonstrate the dependence of the formed complex of properties on the morphology of

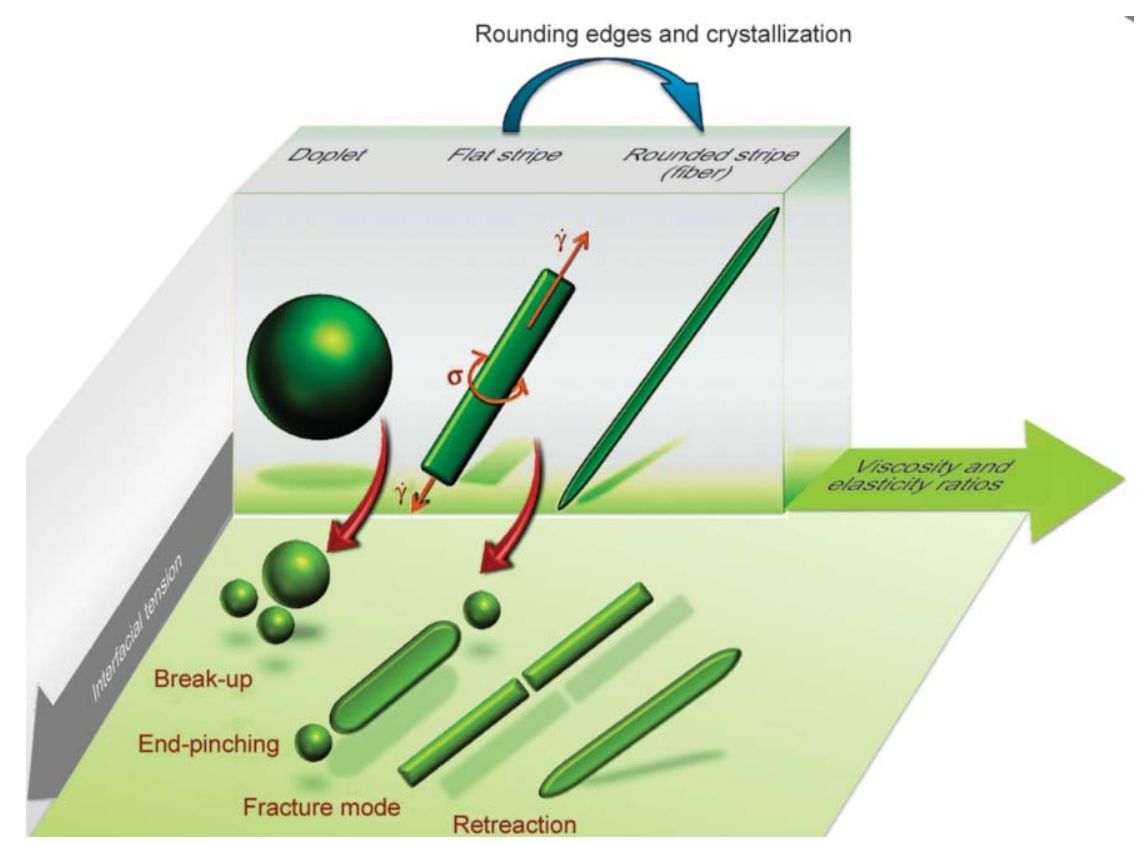

Figure 11. Schematic of PA nanofibers formation and stabilization processes. 
the dispersed component. The formation of nanodroplet structure leads to a significant increase in strain at break and a minor increase in yield strength. In this case, the Young modulus does not change, and the stress at break decreases slightly. In the case of a fibrillar structure, an increase in strain at break and Young modulus is observed. At the same time, the yield stress does not change much, and the stress at break decreases slightly.

\section{Acknowledgements}

The project was financed from funds of the National Science Centre (Poland) on the basis of the decisions number DEC2017/25/B/ST8/02059.

\section{References}

[1] Yu L., Petinakis S., Dean K., Bilyk A., Wu D.: Green polymeric blends and composites from renewable resources. Macromolecular Symposia, 249, 249-250 (2007).

https://doi.org/10.1002/masy.200750432

[2] Sanjay M. R., Siengchin S., Parameswaranpillai J., Jawaid M., Pruncu C. I., Khan A.: A comprehensive review of techniques for natural fibers as reinforcement in composites: Preparation, processing and characterization. Carbohydrate Polymers, 207, 108-121 (2019). https://doi.org/10.1016/j.carbpol.2018.11.083

[3] Omrani E., Menezes P. L., Rohatgi P. K.: State of the art on tribological behavior of polymer matrix composites reinforced with natural fibers in the green materials world. Engineering Science and Technology, an International Journal, 19, 717-736 (2016).

https://doi.org/10.1016/j.jestch.2015.10.007

[4] Lee K-Y., Aitomäki Y., Berglund L. A., Oksman K., Bismarck A.: On the use of nanocellulose as reinforcement in polymer matrix composites. Composites Science and Technology, 105, 15-27 (2014).

https://doi.org/10.1016/j.compscitech.2014.08.032

[5] Megiatto J. D., Oliveira F. B., Rosa D. S., Gardrat C., Castellan A., Frollini E.: Renewable resources as reinforcement of polymeric matrices: Composites based on phenolic thermosets and chemically modified sisal fibers. Macromolecular Bioscience, 7, 1121-1131 (2007). https://doi.org/10.1002/mabi.200700083

[6] Thakur V. K., Singha A. S., Mehta I. K.: Renewable resource-based green polymer composites: Analysis and characterization. International Journal of Polymer Analysis and Characterization, 15, 137-146 (2010). https://doi.org/10.1080/10236660903582233

[7] Rol F., Belgacem M. N., Gandini A., Bras J.: Recent advances in surface-modified cellulose nanofibrils. Progress in Polymer Science, 88, 241-264 (2019). https://doi.org/10.1016/j.progpolymsci.2018.09.002
[8] Jurczuk K., Galeski A., Piorkowska E.: All-polymer nanocomposites with nanofibrillar inclusions generated in situ during compounding. Polymer, 54, 4617-4628 (2013).

https://doi.org/10.1016/j.polymer.2013.06.039

[9] Xu H., Xie L., Chen Y-H., Huang H-D., Xu J-Z., Zhong G-J., Hsiao B. S., Li Z-M.: Strong shear flow-driven simultaneous formation of classic shish-kebab, hybrid shish-kebab, and transcrystallinity in poly(lactic acid)/ natural fiber biocomposites. ACS Sustainable Chemistry and Engineering, 12, 1619-1629 (2013).

https://doi.org/10.1021/sc4003032

[10] Stoclet G., Seguela R., Lefebvre J-M.: Morphology, thermal behavior and mechanical properties of binary blends of compatible biosourced polymers: Polylactide/ polyamide 11. Polymer, 52, 1417-1425 (2011).

https://doi.org/10.1016/j.polymer.2011.02.002

[11] Hosseinnezhad R., Vozniak I., Morawiec J., Galeski A., Dutkiewicz S.: In situ generation of sustainable PLAbased nanocomposites by shear induced crystallization of nanofibrillar inclusions. RSC Advances, 9, 3037030380 (2019).

https://doi.org/10.1039/C9RA05919A

[12] Fakirov S., Duhovic M., Maitrot P., Bhattacharyya D.: From PET nanofibrils to nanofibrillar single-polymer composites. Macromolecular Materials and Engineering, 295, 515-518 (2010).

https://doi.org/10.1002/mame.200900387

[13] Panamoottil S. M., Bhattacharyya D., Fakirov S.: Nanofibrillar polymer-polymer and single polymer composite involving poly(butylene terephthalate): Preparation and mechanical properties. Polymer-Plastics Technology and Engineering, 52, 1106-1112 (2013).

https://doi.org/10.1080/03602559.2013.769583

[14] Ding W., Chen Y., Liu Z., Yang S.: In situ nano-fibrillation of microinjection molded poly(lactic acid)/poly( $\varepsilon$ caprolactone) blends and comparison with conventional injection molding. RSC Advances, 5, 92905-92917 (2015).

https://doi.org/10.1039/C5RA15402B

[15] Voznyak Y., Morawiec J., Galeski A.: Ductility of polylactide composites reinforced with poly(butylene succinate) nanofibers. Composites Part A: Applied Science and Manufacturing, 90, 218-224 (2016).

https://doi.org/10.1016/j.compositesa.2016.07.011

[16] Jašo V., Rodić M. V., Petrović Z. S.: Biocompatible fibers from thermoplastic polyurethane reinforced with polylactic acid microfibers. European Polymer Journal, 63, 20-28 (2015). https://doi.org/10.1016/j.eurpolymj.2014.11.041

[17] Jiang L., Liu B., Zhang J.: Novel high-strength thermoplastic starch reinforced by in situ poly(lactic acid) fibrillation. Macromolecular Materials and Engineering, 294, 301-305 (2009). https://doi.org/10.1002/mame.200900018 
[18] Kimble L. D., Bhattacharyya D., Fakirov S.: Biodegradable microfibrillar polymer-polymer composites from poly(L-lactic acid)/poly(glycolic acid). Express Polymer Letters, 9, 300-307 (2015).

https://doi.org/10.3144/expresspolymlett.2015.27

[19] Yousfi M., Dadouche T., Chomat D., Samuel C., Soulestin J., Lacrampe M. F., Krawczak P.: Development of nanofibrillar morphologies in poly(L-lactide)/ poly(amide) blends: Role of the matrix elasticity and identification of the critical shear rate for the nodular/ fibrillar transition. RSC Advances, 8, 22023-22041 (2018).

https://doi.org/10.1039/C8RA03339K

[20] Kakroodi A. R., Kazemi Y., Ding W. D., Ameli A., Park C. B.: Poly(lactic acid)-based in situ microfibrillar composites with enhanced crystallization kinetics, mechanical properties, rheological behavior, and foaming ability. Biomacromolecules, 16, 3925-3935 (2015).

https://doi.org/10.1021/acs.biomac.5b01253

[21] Vozniak I., Hosseinnezhad R., Morawiec J., Galeski A.: Nanofibrillar green composites of polylactide/polyhydroxyalkanoate produced in situ due to shear induced crystallization. Polymers, 11, 1811-1823 (2019). https://doi.org/10.3390/polym11111811

[22] Li H., Hu G-H.: The early stage of the morphology development of immiscible polymer blends during melt blending: Compatibilized vs. uncompatibilized blends. Journal of Polymer Science Part B: Polymer Physics, 39, 601-610 (2001).

https://doi.org/10.1002/1099-0488(20010301)39:5\%3C601:: AID-POLB1034\%3E3.0.CO;2-V

[23] Tan L-C., Qu J-P.: Characterization of poly(butylene succinate)/poly(lactic acid) blends with in-situ sub-micron fibers and intercalation structure manufacturing by volumetric pulsating elongation flow. Polymer Testing, 77, 105889/1-105889/9 (2019).

https://doi.org/10.1016/j.polymertesting.2019.05.005

[24] Meijer H. E. H., Janssen J. M. H., Anderson P. D.: Mixing of immiscible liquids. in 'Mixing and compounding of polymers: Theory and practice' (ed.: Manas-Zloczower I.) Hanser, Munich, 41-182 (2009).

https://doi.org/10.3139/9783446433717.003

[25] Li H., Sundararaj U.: Morphology development of polymer blends in extruder: The effects of compatibilization and rotation rate. Macromolecular Chemistry and Physics, 210, 852-863 (2009).

https://doi.org/10.1002/macp.200800543

[26] Sundararaj U., Macosko C. W.: Drop breakup and coalescence in polymer blends: The effects of concentration and compatibilization. Macromolecules, 28, 2647-2657 (1995).

https://doi.org/10.1021/ma00112a009
[27] Buell S., Rutledge G. C., van Vliet K. J.: Predicting polymer nanofiber interactions via molecular simulations. ACS Applied Materials and Interfaces, 2, 11641172 (2010). https://doi.org/10.1021/am1000135

[28] He Y., Wu T., Wie J., Fan Z., Li S.: Morphological investigation on melt crystallized polylactide homo- and stereocopolymers by enzymatic degradation with proteinase K. Journal of Polymer Science Part B: Polymer Physics, 46, 959-970 (2008). https://doi.org/10.1002/polb.21430

[29] Marcincin A., Ujhelyiova A., Marcinova T.: Fibre-forming blends of polypropylene and polyethylene terephthalate. Macromolecular Symposia, 176, 65-72 (2001). https://doi.org/10.1002/15213900(200112)176:1\%3C65::AID-MASY65\%3E3.0.CO;2-F

[30] La Mantia F. P., Ceraulo M., Giacchi G., Mistretta M. C., Botta L.: Effect of a compatibilizer on the morphology and properties of polypropylene/polyethylentherephthalate spun fibers. Polymers, 9, 47-61 (2017). https://doi.org/10.3390/polym9020047

[31] Fakirov S., Bhattacharyya D., Lin R. J. T., Fuchs C., Friedrich K.: Contribution of coalescence to microfibril formation in polymer blends during cold drawing. Journal of Macromolecular Science Part B: Physics, 46, 183-194 (2007). https://doi.org/10.1080/00222340601044375

[32] Friedrich K., Evstatiev M., Fakirov S., Evstatiev O., Ishii M., Harrass M.: Microfibrillar reinforced composites from PET/PP blends: Processing, morphology and mechanical properties. Composites Science and Technology, 65, 107-116 (2005). https://doi.org/10.1016/j.compscitech.2004.06.008

[33] Yi X., Xu L., Wang Y-G., Zhong G-J., Ji X., Li Z-M.: Morphology and properties of isotactic polypropylene/ poly(ethylene terephthalate) in situ microfibrillar reinforced blends: Influence of viscosity ratio. European Polymer Journal, 46, 719-730 (2010). https://doi.org/10.1016/j.eurpolymj.2009.12.027

[34] Si X., Guo L., Wang Y., Lau K-T.: Preparation and study of polypropylene/polyethylene terephthalate composite fibres. Composites Science and Technology, 68, 2943-2947 (2008).

https://doi.org/10.1016/j.compscitech.2007.11.008

[35] Fakirov S.: Are the electrospun polymers polymeric fibers? Advanced Materials Letters, 11, 20011456/120011456/3 (2020).

https://doi.org/10.5185/amlett.2020.011456 